have to make sure that people have transport to get to the hospital; you have to have good roads; you need antenatal clinics that are close enough for women to get to for a check up. You have to make sure there are schools so there is a choice for the girls. You have to make sure the nutrition value is different. You have to change the culture of early marriage."

Women prone to fistulas are poor, rural and barely educated, living as they do in a culture which sees the schooling of girls as a "waste," adds Amanuel, who grew up in Ethiopia's taxi-jammed capital. "They're the most voiceless members of our society." Wendy Glauser, Addis Ababa, Ethiopia

DOI:I0.1503/cmaj.080693

\section{Medical whistle-blower}

\section{protection lacking}

W histle-blowing doctors who take stands on behalf of their patients typically have few protections against retaliation.

But that's begun to change in some countries and states, like California, in which hospitals can be fined for reprisals. Some argue such protections should be systematic throughout Canadian medicine.

Their arguments are being bolstered by the experience of Alberta family physician Dr. John O'Connor, who over the past 2 years has found himself embroiled in controversy after publicly surmising that the development of the tar sands was linked to higher rates of cancer in the Northern Alberta town of Fort Chipewyan in which he works.

O'Connor's concerns drew international media attention and have since spawned a pair of investigations.

His statements also prompted an assault on his medical licence, led by 3 physicians who work for Health Canada and who filed complaints about O'Connor with the College of Physicians and Surgeons of Alberta in 2007.

One of those, Dr. Hakique Virani, says the Health Canada trio are con- cerned about O'Connor's practice and conduct, primarily because he failed, they say, when requested by the province, to produce records for the patients he'd claimed had cancer.

Howard May, a spokesperson for Alberta Health and Wellness, says his agency "went out of our way to get Dr. O'Connor to come forward with information, and he didn't do it."

O'Connor disputes this, saying that when he was asked to provide the names of people he knew had specific tumours or cancers, he did.

"I was asked for direct input and I gave them the information."

O'Connor adds that he was accused of causing "undue alarm," but members of the community have told him they are concerned, not alarmed.

He believes his advocacy "has given them the encouragement and the motivation to go ahead." One complaint against O'Connor remains unresolved. (The College declined to investigate another and closed the case on the third).

Spurred by the O'Connor case, the general council of the Canadian Medical Association passed a resolution in 2007 urging that doctors be protected from "reprisal and retaliation" when they speak out as community advocates.

Pressure to protect whistle-blowing doctors and nurses in Canada has also come from public health and legal experts, including the SARS Commission, which concluded in 2006 that health care workers in Ontario need whistleblower protection to ensure they report public health risks promptly and "without fear of consequences."

Manitoba is the only jurisdiction in Canada that now enforces such protection.

It emerged after a 1994 dispute in which anesthesiologists at the Winnipeg Health Sciences Centre boycotted the hospital's cardiac surgery program and asked administrators to review its safety. The doctors were forced back to work under threat of losing their jobs.

A subsequent pediatric cardiac surgery inquest found that several deaths in the program could have been prevented and led, in turn, to Manitoba Regulation 64/2007, which protects healthcare professionals from reprisals when they make complaints about the quality of clinical care.

Similar protections are more widespread in the United States, where the Joint Commission on the Accreditation of Hospitals prohibits retaliatory action.

California has gone a step further, mandating that once a complaint is made, reprisals within 4 months are presumed to be retaliation, and the hospitals can be fined up to US $\$ 25000$. Miriam Shuchman MD, Toronto, Ont.

DOI:I0.1503/cmaj.080694

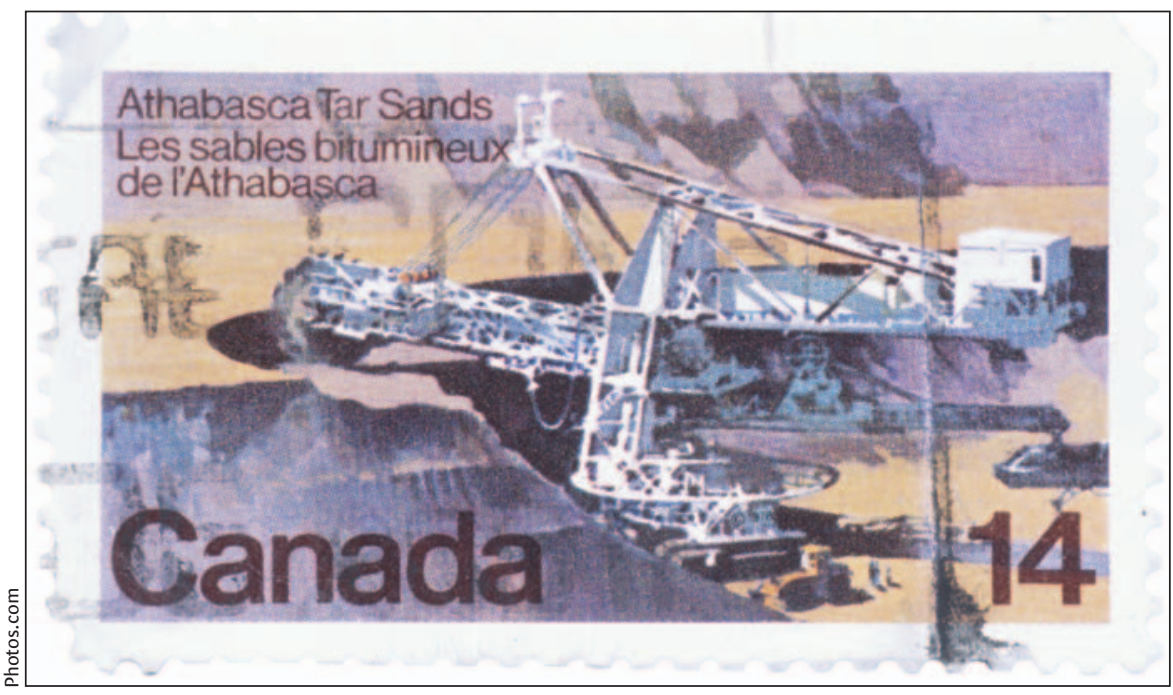

The Athabasca tar sands have been linked by Dr. John O'Connor to "clusters of diseases" among his patients in Fort Chipewyan, Alberta. O'Connor was accused by Health Canada of "causing undue alarm" and "blocking access to data" in his patient files. 